\title{
Basat en fets reals: processos i (in)cultura
}

\section{Based on real events: processes and in(culture)}

\author{
Josep CAPDEFERRO \\ josep.capdeferro@upf.edu
}

Universitat Pompen Fabra

A Eva Serra Puig i Jaume Riera Sans, lectors $\mathrm{i}$ analistes àvids de processos,

in memoriam

Aquest monogràfic, que consta de vuit articles, té per objecte la reivindicació dels processos judicials com a font de primer ordre per al coneixement de la cultura escrita medieval i moderna -que no necessàriament es correspon amb societats àmpliament alfabetitzades i cultes, com es veurà en diverses contribucions. L’expressió «Basat en fets reals» del títol vol subratllar que els processos solen tenir un contingut substancial d'esdeveniments empírics, contrastables, però també una dosi gens menyspreable de subjectivitats de tots els intervinents que, en va, pretenen recrear-los amb exactitud.

A les societats preliberals de l'extinta Corona d'Aragó, de processos n'hi havia de moltes menes i davant un caramull de jurisdiccions: seculars o eclesiàstiques, reials, senyorials o municipals, patrimonials -feudals o emfitèutiques-, civils o militars, de mer o de mixt imperi -que, en certs aspectes, correspondrien a plets de dret criminal o de dret privat-, contencioses o voluntàries, regulars o fiscalitzadores - purgues de taula, visites règies, del General, municipals, pastorals... -, excepcionals com la inquisitorial, òrgans disciplinaris que sovint usurpaven facultats alienes, etc. I sovintejaven els conflictes entre diverses jurisdiccions, que obligaven a processos - de vegades complexíssims- 
per delimitar els respectius àmbits competencials. En societats iuscentristes com les nostres, on les voluntats i pretensions de cadascú s'expressaven en termes de Dret, la instrucció d'un procés era pa de cada dia. Com passa avui mateix, rere la façana de processos formalment jurídics s'instruien judicis polítics i es defenestraven rivals o enemics del Poder establert. No existia res similar a la separació de poders, és clar, i es qualificaven com a processos dossiers contradictoris que avui consideraríem plets judicials i altres que rebaixaríem a la condició d'expedients administratius. Fins i tot un àmbit aparentment llunyà com seria el legislatiu, el de les antigues Corts de base estamental, operava com un gran procés amb habilitacions temporals i personals i fases prefixades que calia respectar perquè les deliberacions i els decrets fossin vàlids; dins de cada procés parlamentari, endemés, tenien lloc processos específics com els d'enjudiciament de greuges o els judicis en cort.

A l'edat moderna, la litigiositat es va incrementar de forma desmesurada als territoris de la Corona d'Aragó, de la monarquia Hispànica i del conjunt d'Europa. I, almenys als nostres països, no estava reservada a gent acomodada, sinó que moltes persones i comunitats hi recorrien i hi esmerçaven gran quantitat de diners per fer valdre els seus drets. No cal dir que això comportà una inflació dels processos. Als nostres verals, el desenvolupament de la mà de la monarquia de noves institucions d'alta judicatura $-i$, sovint, una resiliència de les preexistents vinculades a altres poders- ha estat estudiat de forma asimètrica els darrers anys. La Reial Audiència de València i la de Mallorca compten amb estudis prou complets; en canvi, de la de Catalunya únicament s'han analitzat les trajectòries vitals, no sempre previsibles, dels homes que en formaren part. Hi ha molta feina pendent si volem emmirallar-nos en França, on la història de la justícia preliberal i contemporània ha conegut un progrés enorme.

No cal dir que fer recerca sobre tribunals, institucions i processos jurisdiccionals, del tipus que sigui, aboca a conèixer solucions més o menys justes que cada societat donava als problemes, generalment en forma de sentències, provisions o interlocutòries - però també arbitratges o concòrdies, 'concerts' com en dirien fa segles. I convida a esbrinar de quina manera aquestes resolucions serien sovint comentades per juristes de prestigi o per jutges de referència $i$, així, establirien un precedent a tenir en compte en casos similars que es puguessin plantejar en un futur. Els nostres ordenaments jurídics, de fet, històricament estaven molt més construïts sobre la jurisprudència judicial del que s'ha pensat durant anys -en el món liberal, la primacia de la llei i el codi han eclipsat realitats antigues més casuístiques i jurídicament més pluralistes. Però avui aquí ens interessem pels processos en si mateixos, més que no pas pels seus efectes sobre el cas jutjat o altres a venir. Processos, com he dit amunt, on incidien diferents subjectivitats: les veritats respectives de les parts en confrontació, els drets i els arguments al legats pels advocats, la centralitat de la prova -llavor de presumpcions, conjectures i altres elucubracions-, la vivacitat de les declaracions testificals -sovint interessades per corporativisme o altres motius-, les resolucions més o menys motivades -i jurídicament millor o pitjor-, incidències processals, suplicacions i cèdules, causes d'atemptats, mesures cautelars, vies de constrenyiment... 
El dels processos no és pas un filó nou per a la historiografia, però sí que s'està intensificant, com va passar amb les fonts epistolars o les dietarístiques, sovint amb una perspectiva microhistòrica pensem, per exemple, en el procés de la visita de les Coves de Vinromà de 1617 estudiat per Vicent J. Escartí, el procés contra la revolta de l'any 1640 a Tortosa, de la mà de Joan-Hilari Muñoz, o tres processos del Ripollès sobre assassinats, bruixes i encanteris analitzats per Joan Antoni Padrós, per posar només tres exemples recents. Comprensiblement, d'entre els molts tipus de processos, els penals i inquisitorials són els que tenen més tirada entre els estudiosos de la cultura, la llengua i el passat en general. Aquest monogràfic n'és un testimoni més. Com no pot ser altrament, en la matèria que ens ocupa es va enfortint la perspectiva de gènere. Tot i que avui i aquí, cal dir-ho, suspenem pel que fa a autoria de manera ignominiosa -només una dona i set homes-; en canvi, aprovem amb nota -malauradament- en el còmput de dones objecte dels processos analitzats, gràcies a les dues esposes poliàndriques de l'article d'Àlex Llinares i, sobretot, al centenar i mig de bruixes d'àmbit andorrà de la base de dades que presenta Pau Castell. Des d'aquestes al lusions, passo a glossar breument què trobareu a cada article del monogràfic.

Vull advertir que ordenar els textos ha estat un maldecap. Les vuit peces del puzzle no encaixaven bé amb cap dels criteris que a priori hauria desitjat aplicar: cronològic, jurisdiccional o temàtic -l'alfabètic dels cognoms dels autors havia quedat descartat d'entrada perquè qui escriu aquestes ratlles ni volia ni mereixia figurar en primer lloc. Finalment, m'he inclinat per un criteri territorial, de sud a nord de les terres de parla catalana. El punt de partida del recorregut són la ciutat i el regne de València, on els processos penals han estat, són i previsiblement continuaran essent objecte d'aportacions historiogràfiques principals: en primer lloc, entra en escena una justícia d'àmbit municipal a final del segle XIV (Guillermo López Juan); segonament, la justícia del rei a la segona meitat del XVI ( $\mathrm{M}^{a}$ Dolores Hernández); en tercer lloc, la Inquisició d’àmbit valencià entre els segles XVI i XVIII (Jacob Mompó, Àlex Llinares i Albert Toldrà, ordenats així per l'any del primer cas estudiat). Acte seguit, el lector és traslladat al Principat de Catalunya i pot llegir dos articles relacionats amb el General -el principal poder de la província, representat regularment a través de la Diputació del General o Generalitat-: un té per seu Barcelona i l'he escrit jo amb la col laboració d'Adrià San Miguel, que poc a poc s'encamina en la recerca; l'article de Torra en part està ambientat a Barcelona i en part s'enfila cap al Pirineu nord-català, en concret a la Vall del Conflent. Com a fi de trajecte, l'article de Pau Castell eleva el monogràfic a les Valls d'Andorra; fa d'herald d'una iniciativa d'humanitats digitals que, tot cavalcant entre la recerca i la divulgació, tusta la porta del futur. Explorem-los tot vuit pam a pam.

Guillermo López Juan ha confegit «Les males paraules: insults masculins a la València baixmedieval» a partir de processos instruïts pel justícia criminal de València -l'oficial municipal encarregat de jutjar i castigar els delictes a la ciutat-; tals processos havien començat amb clams verbals o denúncies per escrit de menestrals $i$ altres persones comuns que es consideraven injuriades i deshonrades, com a individus i com a membres d'un llinatge, per paraules malsonants pronunciades públicament-sovint, acompanyades d'actes de desdeny o de violència física. Més enllà d'identificar i contextualitzar 
els insults, els grups socials menestrals que solien rebre'ls -molts agents de l'autoritat, que avui es considerarien víctimes de delictes d'odi- i els que en solien proferir, l'autor enllaça els seus resultats amb estudis antropològics de base sobre l'honor i la seva relativa relativitat -si es permet la redundància- a la Mediterrània occidental a final del segle XIV.

María Dolores Hernández-Fernández signa «Procesos criminales a instancia de parte privada. Apuntes sobre su praxis en el Real Consell Criminal valenciano en época de Felipe II», testimoni d'una imminent i prometedora tesi doctoral, lleial als ensenyaments de Teresa Canet Aparici. El fons potencial per a les seves recerques futures és immens i molt rar a l'àmbit ibèric: sis mil processos criminals custodiats a l'Arxiu del Regne de València. De moment, ha començat per processos de les dècades de 1560 i 1570, per la coincidència de diversos factors rellevants, principalment l'erecció del Real Consell Criminal a les Corts de 1564 i la creixent preocupació règia per la cronificació de problemes greus com les bandositats, el bandolerisme, la pirateria i el control dels moriscos. El seu text, el més deliciosament històrico-jurídic del monogràfic, mostra com, des de la primera dècada del segle XVI, la Reial Audiència del Regne havia anat assumint mitjançant avocacions de causes criminals greus instades per litigants i decretades per la Cancelleria reial, el coneixement de casos que a priori haurien correspost a jurisdiccions inferiors. I, poc a poc, havia anat teixint una praxi judiciària molt garantista que aconseguiria encaixar l'alta justícia règia en el sistema foral secular del regne.

Amb «La Inquisició de València contra Vicent Navarro (1750-1757), Diego Ramírez (1742) i Pedro Navarro (1588), tres casos de 'sodomia bestial'», Jacob Mompó enceta el lot de tres articles sobre processos davant la Inquisició valenciana -si bé un havia estat vist parcialment per la saragossana. El seu article enllaça hàbilment amb un altre que publicà al número 12 de Scripta. Els tres reus són acusats de bestialisme; un d'ells, de fet, és investigat per bestialisme passiu i també sodomia i hermafroditisme. Hi ha fragments de les transcripcions dels processos, especialment la sessió de torment a Pedro Arbones, que són d'una cruesa esfereïdora. Dos dels reus - del tercer no se'n sap el desenllaç-, tot i ser fortament castigats, acaben rebent penes menys severes que la capital legalment prevista pels seus pecats i crims -que se superposen-, en línia amb el que Jaume Riera i Sans apuntà per a alguns casos en la seva obra magna Sodomites catalans.

El text d'Àlex Llinares es titula «Una aproximació microhistòrica a la bigàmia femenina en el Regne de València» i està confegit sobre dos processos inquisitorials de poliàndria, el de la benissera Anna Maria Ivars del segle XVII i el de la callosina Maria Francisca Saval de finals del XVIII. Llinares, lluny de metodologies quantitatives, presta una atenció minuciosa als dits processos tot cercant circumstàncies afectives o de mobilitat geogràfica que podien dur dues dones de la Marina a comprometre's cadascuna amb dos marits vius, no obstant els preceptes de dret canònic, fortificats amb els decrets del Concili de Trento i els aires de disciplinament religiós duts pel segle XVI. El cas Saval podria semblar l'esborrany d'el guió d'una telenovel la: escapant d'uns suposats maltractaments del seu primer marit, Maria Francisca se'n va a servir a Alacant; hi troba l'amor en 
braços d'un genovès; naveguen fins a Roma, on aconsegueixen casar-se; a Torí reben un passaport que els permet creuar països tot feinejant-hi; són detinguts quan tornen a passar per territoris de la Corona d'Aragó, amb la qual cosa se'ls frustra la presumible ambició d'iniciar una vida nova a les amèriques.

Albert Toldrà amb «La caiguda de Felicià Piquer, bruixot processat per la Inquisició de València (1669-1673)» continua una línia de treball ben consolidada que s'ha reflectit en dues monografies aquesta dècada, amb inicis de títol eloqüents com En nom de Déu i Per la reixeta. Colpeix la ignorància de força joves dissortades davant d'un farsant carregat de sortilegis que, amb el pretext d'ajudar-les a buscar tresors encantats i ocults, l'únic que trobava era la manera de fer-los perdre la virginitat. Aquesta ignorància i la naturalitat amb què les donzelles relaten la perversió del cercatresors fan desaconsellable l'esplèndida trama a menors. En canvi, la gaudirà el públic que busqui una combinació equilibrada d'història social, cultural i també institucional, car Toldrà ressegueix amb gran rigor el llarg i complex periple processal que patí Piquer davant diverses instàncies jurisdiccionals inquisitorials i reials i n'identifica curosament els participants - entre ells, qualificadors i familiars del Sant Ofici- i les seves prerrogatives respectives.

Jo mateix, amb el suport d'Adrià San Miguel, he escrit «Los hòmens no són perfets: revelacions dels processos de fiscalització institucional». Ras i curt, hi expliquem oportunitats de recerca poc previsibles de l'immens fons de processos de la visita del General de Catalunya entre final del segle XVI i principi del XVIII. En paral lel, tot convertint en secundari un argument que podria ser central, resseguim les principals funcions -i disfuncions- de la Diputació, que naturalment també es poden documentar amb aquest fons, pràcticament verge. Incidim en quelcom poc freqüent: la percepció que tenien alguns denunciants d'haver estatt tractats de forma arrogant o abusiva per part dels càrrecs i agents de l'antiga Generalitat. Impressions subjectives de l'època com aquesta difícilment ens arribarien si no fos a través de processos. És gràcies a processos de visita i d'altra mena que durant el primer tram de la meva carrera acadèmica he pogut estudiar un munt de coses; entre elles, a tall d'exemple: la repressió que Diputació del General i Consell de Cent van intentar infligir a Francesc Martí Viladamor per haver estat més lleial a Lluís XIV de França que als interessos de la Catalunya secessionista dels anys 1640; part de la meva tesi doctoral -tot creuant processos amb al legacions jurídiques, literatura jurídica i, sobretot, correspondència entre advocats, procuradors i clients-; amb Jaume Ribalta al llibre Banyuts catalans, una visió panoràmica sobre la Casa de les Egipcíaques de Barcelona -un correccional on eren custodiades dones adúlteres de classes populars entre els segles XV i XVIII; dones treballadores a la Barcelona moderna; conflictes pesquers i d'atermenament territorial a l'antic comtat d'Empúries; discriminacions actives i latents envers descendents de judeoconversos al cor de Catalunya, etc. Escau, a més de seguir investigant amb aquesta tipologia de fonts, compartir la destresa adquirida amb investigadors de properes generacions.

Ricard Torra, a «Territori i relacions institucionals a la Catalunya del sis-cents. Tres estudis de cas a 
partir dels processos de la Visita del General de Catalunya», un any després d'haver-se doctorat amb una tesi sobre la Visita del General elaborada fonamentalment a partir de sentències fiscalitzadores -i moltes altres fonts, és clar-, creua el rubicó i s'endinsa, ell també, en el casuístic món dels processos. Fa visibles interioritats de la Diputació tant pel que fa a l'organització dels districtes fiscals territorials $i$ les funcions dels seus diferents agents com a les disputes, durant el procés fiscalitzador, entre visitadors acusats de dispendiosos i consistoris de diputats i ö̈dors de comptes a la defensiva. Així, posa en evidència que els estudis de Miquel Pérez Latre i Eva Serra van obrir molts camins que mereixen ser explorats. La recerca de Torra, posada en el context d'altres estudis sobre frau o corrupció a l'Europa moderna -nocions en contínua revisió-, està cridada a traspassar fronteres aviat.

Finalment, Pau Castell aporta «El projecte terradebruixes i els processos per bruixeria andorrans: entre la recerca històrica i la divulgació», on presenta una base de dades activa -i interactiva- des de març del 2019, creada amb el suport de l'Arxiu Nacional d'Andorra i el Govern d'Andorra a partir d'una seixantena de plecs processals produits davant del Tribunal de Corts andorrà entre la dècada de 1420 i la de 1640 i material complementari. A partir de fitxes, enllaços, paraules clau i mapes, el públic hi pot trobar les dades que li interessin segons filtres geogràfics, temàtics, onomàstics, genealògics, etc. Amb projectes com aquest, que és de justícia donar a conèixer, la recerca científica dels diferents àmbits de les ciències humanes i socials sens dubte s'agilitzarà.

En un moment d'involució de drets i llibertats com el que vivim i temem, només el coneixement podrà evitar una regressió a realitats polítiques i socials enfangades en l'estigma, la discriminació, la superstició i la corrupció. 